\title{
Codes of new generation for safety justification of power units with a closed nuclear fuel cycle developed for the "PRORYV" project
}

\author{
Leonid A. Bolshov ${ }^{1}$, Valery F. Strizhov ${ }^{1}$, Nastasya A. Mosunova ${ }^{1}$ \\ 1 Nuclear Safety Institute of the Russian Academy of Sciences, Moscow, Russia \\ Corresponding author: Nastasya Mosunova (nam@ibrae.ac.ru)
}

Academic editor: Andrei Rineiski • Received 25 May 2020 • Accepted 5 October 2020 • Published 6 November 2020

Citation: Bolshov LA, Strizhov VF, Mosunova NA (2020) Codes of new generation for safety justification of power units with a closed nuclear fuel cycle developed for the "PRORYV" project. Nuclear Energy and Technology 6(3): 203-214. https://doi. org/10.3897/nucet.6.54710

\begin{abstract}
The article describes the status of development of codes of new generation for the "PRORYV" Project by the end of 2019: twenty-five commercial-grade software products to justify design solutions and safety of power units with fast neutron reactors and liquid metal coolant (sodium and lead) in a closed nuclear fuel cycle. The developed system of codes is multi-physical and multi-scale that allows performing both calculations of the whole installations and high precision calculations of their individual elements. The developed codes offer unique features. Twelve developed codes have already been certified by Rostechnadzor, and six more have been submitted for certification. In addition to creating the software products, a large-scale work is being carried out to conduct experimental studies for code validation that meet modern requirements imposed by the codes: unique measurement techniques have been created; experimental data on flow characteristics of heavy liquid metal coolant (HLMC) in a fuel assembly simulator have been obtained, as well as of "gas-HLMC" interphase interaction after inert gas injection in HLMC and characteristics of heat exchange between the inert gas and HLMC. The results are already used for validation of system and CFD codes used in the "PRORYV" Project.
\end{abstract}

\section{Keywords}

code of new generation, "PRORYV" Project, code validation, MNUP fuel, EUCLID/V2 code, BERKUT-U code

\section{Abbreviations}

$\begin{array}{ll}\text { DPA } & \text { Displacement Per Atom } \\ \text { ECCS } & \text { Emergency Core Cooling System } \\ \text { FA } & \text { Fuel Assembly } \\ \text { FIMA } & \text { Fissions per Initial heavy Metal Atom } \\ \text { FR } & \text { Fast Reactor } \\ \text { FP } & \text { Fission Products } \\ \text { HLMC } & \text { Heavy Liquid Metal Coolant } \\ \text { IHX } & \text { Intermediate Heat eXchanger }\end{array}$




\begin{tabular}{|c|c|}
\hline МСР-1 & $\begin{array}{l}\text { Main Circulation Pump of the primary } \\
\text { coolant system }\end{array}$ \\
\hline МСР-2 & $\begin{array}{l}\text { Main Circulation Pump of the secon- } \\
\text { dary coolant system }\end{array}$ \\
\hline MNUP fuel & Mixed Nitride Uranium-Plutonium fuel \\
\hline MOX fuel & Mixed Oxide Uranium-Plutonium fuel \\
\hline NPP & Nuclear Power Plant \\
\hline RANS & $\begin{array}{l}\text { Reynolds-Averaged } \\
\text { equations }\end{array}$ \\
\hline RC & Reactor Core \\
\hline RI & Reactor Installation \\
\hline Rostechnadzor & $\begin{array}{l}\text { Federal Environmental, Industrial and } \\
\text { Nuclear Supervision Service of Russia }\end{array}$ \\
\hline RW & Radioactive Waste \\
\hline SG & Steam Generator \\
\hline TRL & Technology Readiness Levels \\
\hline
\end{tabular}

\section{Introduction}

One of unique projects being successfully realized in the Russian Federation is the "PRORYV" Project, aimed at developing power complexes with FRs in a closed nuclear fuel cycle. Due to a competently built system of scientific and technical management, consolidation of highly qualified result-motivated and wide-profile specialists, the availability of a unique experimental base, a stable funding, significant results were achieved in a short period of time: a technology for the production of MNUP fuel was created and experimental studies were performed that confirmed its efficiency; designs of FRs with lead (BREST-OD-300) and sodium (BN-1200) coolants have been developed; construction of pilot-demonstration facilities of a power unit with BREST-OD-300 and CNFC has been started.

Due to the project innovative nature, it would be impossible to obtain such results without using the potential and achievements in the field of mathematical modeling. This article covers the "Codes of new generation" subproject of the "PRORYV" Project and software products 1 developed within it. The "code of new generation" means commercial-grade software with the following characteristics:

- based on the state-of-the-art level of theoretical knowledge and experimental data on physical processes and phenomena;

- uses efficient numerical algorithms;

- written in accordance with the up-to-date requirements of programming language standards and adapted to state-of-the-art computer technology;

- has a friendly user interface;

- equipped with a full package of documentation (user guide, programmer guide, reference manual);

- has automatic interface with CAD data².

\footnotetext{
1 In the article, the phrases "code of new generation", "software product" and "software" are synonymous.

2 For multidimensional codes.
}

General information on "Codes of new generation" project is briefly presented in (Bol'shov et al. 2016; Strizhov et al. 2017). The purpose of this article is to acquaint the NUCET Journal readers with the latest achievements in this field.

\section{The list and status of the codes of new generation development by the end of 2019}

The work on the "Codes of new generation" project started in 2010. At this time, the need was recognized to develop a system of broad-scoped software products. Likewise with other large-scale projects, the first years were spent for the development of technical specifications and detailed technical requirements. The large-scale development of the software products began in 2012.

First, the task was set to develop 17 codes; by 2019 their number had increased to 25 , which was associated with an awareness of the possibilities and advantages of using state-of-the-art software systems.

The general information about the designation and development status of the codes of new generation is presented in the Table 1, including their Technology Readiness Levels (TRL).

Compared to earlier publications (Bol'shov et al. 2016; Strizhov et al. 2017), significant progress should be noted in expanding the applicability areas of codes, the status of their validation and certification in Rostechnadzor. In addition, the codes of new generation package includes the codes for modeling of the installations of the closed nuclear fuel cycle, including 3D multi-component thermohydraulic models, the development of which was started in 2019.

The information about some of the most interesting models in the opinion of the article authors, included in the codes in 2018-2019, as well as the validation results is represented in the Section 3. Detailed information can be found in individual publications, which are referenced in this article.

\section{Summary of some new models of the codes of new generation and the results of their validation in 2018-2019}

\subsection{Improved (mechanistic) fuel code BERKUT-U}

The advanced fuel code BERKUT-U is designed to calculate the thermo-mechanical behavior and justify the operability of single fuel rod with an oxide (uranium dioxide and MOX) and nitride (uranium mononitride and MNUP) pellet fuel, with a gas gap or a liquid metal gap, in normal and abnormal operation modes of advanced FRs with liquid metal coolant. 
Table 1. The development status of the codes of new generation by the end of 2019 .

\begin{tabular}{|c|c|c|c|c|}
\hline Code name & Brief description & Development status & TRL level & References \\
\hline \multicolumn{5}{|c|}{ Probabilistic safety assessment } \\
\hline CRISS 5.3 & Code for probabilistic safety assessment & Validated, certified & 9 & Abramov et al. 2016 \\
\hline \multicolumn{5}{|c|}{ Fuel rod behavior } \\
\hline BERKUT* & $\begin{array}{l}\text { Code for analysis of fuel rod behavior in normal and abnormal operation } \\
\text { modes, engineering version }\end{array}$ & Validated, certified & 9 & Veprev et al. 2018,2020 \\
\hline BERKUT-U* & $\begin{array}{c}\text { Code for analysis of fuel rod behavior in normal and abnormal operation } \\
\text { modes, advanced (mechanistic) version }\end{array}$ & $\begin{array}{c}\text { Validated, in the process } \\
\text { of certification }\end{array}$ & 8 & Boldyrev et al. 2020 \\
\hline \multicolumn{5}{|c|}{$\begin{array}{ll} & \text { Neutronics }\end{array}$} \\
\hline MCU-FR*,** & Neutronic code based on the Monte-Carlo method & $\begin{array}{c}\text { Validated, in the process } \\
\text { of certification }\end{array}$ & 8 & $\begin{array}{l}\text { Kalugin et al. } 2015 \text {; } \\
\text { Gurevich et al. } 2016\end{array}$ \\
\hline ODETTA $* *^{*}$ & $\begin{array}{l}\text { Neutronic code for shielding calculations based on the } \mathrm{S}_{\mathrm{n}} \text { method and the } \\
\text { finite element method }\end{array}$ & Validated, certified & 9 & Belousov et al. 2018 \\
\hline CORNER $*, * *$ & Neutronic code based on the $\mathrm{S}_{\mathrm{n}}$ method and the finite difference method & $\begin{array}{c}\text { Validated, in the process } \\
\text { of certification }\end{array}$ & 8 & Bereznev et al. 2015 \\
\hline DOLCE VITA $* * *$ & Neutronic code based on diffusion approximation & $\begin{array}{c}\text { Validated, in the process } \\
\text { of certification }\end{array}$ & 8 & Seleznev et al. $2018 \mathrm{a}$ \\
\hline $\mathrm{BPSD}^{*}, * *$ & Nuclide kinetics code, for calculation of activity and residual decay heat & $\begin{array}{c}\text { Validated, in the process } \\
\text { of certification }\end{array}$ & 8 & Seleznev et al. $2018 \mathrm{~b}$ \\
\hline COMPLEX & $\begin{array}{l}\text { System of codes for the radiation safety justification of a FRs installation } \\
\text { and fuel cycle facilities }\end{array}$ & Under development & 5 & Belov et al. 2019 \\
\hline \multicolumn{5}{|c|}{ Thermohydraulics } \\
\hline $\begin{array}{l}\text { HYDRA-IBRAE/ } \\
\text { LM/V1* }\end{array}$ & System (channel) thermal-hydraulic code & Validated, certified & 9 & $\begin{array}{l}\text { Alipchenkov et al. 2016; } \\
\text { Mosunova et al. } 2020\end{array}$ \\
\hline LOGOS & RANS CFD code & $\begin{array}{l}\text { Validated, filed for } \\
\text { certification }\end{array}$ & 8 & Kozelkov et al. 2016 \\
\hline CONV-3D & DNS CFD code & Validated, certified & 9 & $\begin{array}{l}\text { Chudanov et al. 2017, } \\
2020\end{array}$ \\
\hline CONV-3D/TwoPhase & DNS CFD code expanded to two-phase simulations & Under development & 3 & $\begin{array}{l}\text { Chudanov et al. 2016, } \\
2019\end{array}$ \\
\hline KUPOL-BR & $\begin{array}{c}\text { Code for modeling heat and mass transfer processes in reactor containment } \\
\text { building }\end{array}$ & $\begin{array}{c}\text { Validated, in the process } \\
\text { of certification }\end{array}$ & 8 & Vitushkina et al. 2006 \\
\hline \multicolumn{5}{|c|}{ Fission products transport } \\
\hline ROM* & Code for assessing the radiation situation outside the NPP site & Validated, certified & 9 & Dzama et al. 2019a \\
\hline ROUZ & $\begin{array}{l}\text { Code for assessing the on-site NPP radiation situation taking into account } \\
\text { the 3D built-up environment }\end{array}$ & Validated, certified & 9 & Dzama et al. 2019b \\
\hline Sybilla & Code for modeling of radioactivity migration in reservoirs & Validated, certified & 9 & Krylov et al. 2016 \\
\hline $\mathrm{GeRa} / \mathrm{V} 1$ & Code to assess the safety of radioactive waste disposal & Validated, certified & 9 & $\begin{array}{l}\text { Kapyrin et al. } 2015 \text {; } \\
\text { Novikov et al. } 2020\end{array}$ \\
\hline \multicolumn{5}{|c|}{ Multiphysics codes } \\
\hline $\begin{array}{l}\text { SOCRAT-BN/V1 } \\
\text { SOCRAT-BN/V2 }\end{array}$ & $\begin{array}{l}\text { Comprehensive analysis of normal and abnormal operation modes, } \\
\text { including severe accidents, for NPPs RI with sodium coolant and oxide fuel }\end{array}$ & $\begin{array}{l}\text { Validated, certified } \\
\text { Validated, certified }\end{array}$ & $\begin{array}{l}9 \\
9\end{array}$ & Usov et al. 2012 \\
\hline $\begin{array}{l}\text { EUCLID/V1 } \\
\text { EUCLID/V2 }\end{array}$ & $\begin{array}{c}\text { Comprehensive analysis of normal and abnormal operation modes, } \\
\text { including accidents, for NPPs RI with sodium, lead and lead-bismuth } \\
\text { coolant and fuel rods with oxide or nitride fuel }\end{array}$ & $\begin{array}{l}\text { Validated, certified } \\
\text { Partially validated }\end{array}$ & $\begin{array}{l}9 \\
5\end{array}$ & $\begin{array}{l}\text { Mosunova 2018; } \\
\text { Alipchenkov et al. } 2018 \\
\text { Butov et al. 2019a, b }\end{array}$ \\
\hline \multicolumn{5}{|c|}{ Models of closed nuclear fuel cycle processes and installations } \\
\hline VIZART & Code to simulate the balance of materials and nuclide flows in the CNFC & Partially validated & 8 & Shmidt et al. 2017 \\
\hline TP CODE & Code to simulate the work of technological schemes & Partially validated & 8 & Goryunov et al. 2018 \\
\hline $\begin{array}{l}\text { Precision } \\
\text { computational } \\
\text { models for the CNFC } \\
\text { facilities }\end{array}$ & Precise calculation models for the CNFC facilities & Under development & 3 & - \\
\hline
\end{tabular}

A distinctive feature of the code is the presence of a mechanistic fuel behavior module, the prototype of which was the MFPR/R fuel code (Veshchunov et al. 2006; Veshchunov et al. 2007), simulating the behavior of oxide fuel in thermal reactors under normal and emergency conditions. The fuel behavior module of the BERKUT-U code includes four basic macromodels: (1) breeding process and FP radioactive decay; (2) the evolution of the fuel microstructure and FP intragranular transport; (3) the formation of intergranular porosity, intergranular transport and FP release into open porosity; (4) thermodynamics of burnt fuel, the formation of FP chemical compounds and their distribution over phase states. The evolution of the fuel microstructure, the formation of FP gas and conden- sed phases and FP transport are modeled, which makes possible to predict the fuel swelling and FP release under fuel rod cladding and, consequently, the change of the fuel thermo-physical characteristics, pressure and thermal conductivity of gas gap as fuel burns out, and in the case of depressurization - the FP amount injected in the coolant.

When developing the fuel module as part of the BERKUT-U fuel code, it was taken into account that most of processes in oxide fuel are common for thermal and fast neutron reactors, so that the corresponding particular models developed earlier for thermal reactors can also be used for calculations of FRs. Moreover, the functional form of code models is also mainly suitable for describing processes in nitride fuel, since they have similar physics with 
oxide fuel. However, the microscopic parameters of models for oxide and nitride fuels often differ greatly, and for nitride fuel, these parameters are usually poorly known or not determined at all. To identify them, the experimental data obtained from the studies of nitride fuel after its irradiation in a reactor have been used, as well as the results of atomistic modeling (Veshchunov et al. 2015; Tarasov and Polovnikov 2017; Starikov et al. 2017). In addition, new models were developed or existing ones were improved to describe thermochemical processes in nitride fuel, capture of gaseous fission products by technological porosity, helium diffusion, and also impurities (oxygen, carbon) with the formation of secondary oxide and carbide phases.

By mid-2019, the models for nitride fuel were validated on the results of post-reactor studies of BORA-BORA fuel rods irradiated in the BOR-60 reactor, KETVS-1, 2, 3, 6, 7 and ETVS-4, 5 experimental assemblies irradiated in the BN-600 RI. These studies provided experimental data concerning the behavior of fission products in the fuel, their release into the fuel-cladding gap, the mechanical state of the fuel pellets and the fuel element as a whole. In particular, for MNUP fuel, the content of plutonium varied from 10 to $60 \%$, maximum burn-up - from 3.5 to $12 \%$, and damaging doses - from 20 to $70 \mathrm{DPA}$, maximum temperatures - from 1100 to $1700{ }^{\circ} \mathrm{C}$.

The results show that the BERKUT-U calculation code allows describing the entire existing experimental data array on the fission products release and the mechanical state of the fuel with a fairly good accuracy. The change in the size of fuel pellets is calculated with an accuracy of $1-2 \%$, the fuel swelling - on average $30-40 \%$, the swelling rate $-30 \%$, and the release of gaseous fission products $-30-50 \%$. These results can be considered satisfactory taking into account the uncertainties of the experimental measurements. Unlike engineering techniques, the BERKUT-U code allows predicting the isotopic and molecular-phase compositions of irradiated fuel, as well as obtaining axial and radial distributions of porosity, actinides and fission products.

Examples of such results are presented in Figures 1 and 2. The fuel rod with mixed uranium-plutonium nitride fuel (U0.55Pu0.45) N without a central hole and with a helium gas gap of the BORA-BORA experiments irradiated in the BOR-60 fast reactor was considered. The maximum burn-up for this fuel rod was equal to $9.4 \%$ FIMA (Rogozkin et al. 2013). The calculated and experimental distributions of porosity (Fig. 1) and fission products (Fig. 2), Cs and Mo, along the pellet radius in the central part of a fuel rod are shown. In Figure 1, the NM variant is the calculation for the case of the nominal sizes of the fuel pellets; the CT variant corresponds to a reduced diameter within the technological tolerance $(0.1 \mathrm{~mm})$. The reduction of porosity in Figure 1 is caused by the reduction of temperature of the fuel pellets with pellets radius.

Currently, the consolidation and analysis of the results of the BERKUT-U code validation is being completed. At the end of 2019, the code was submitted for certification to Rostechnadzor.

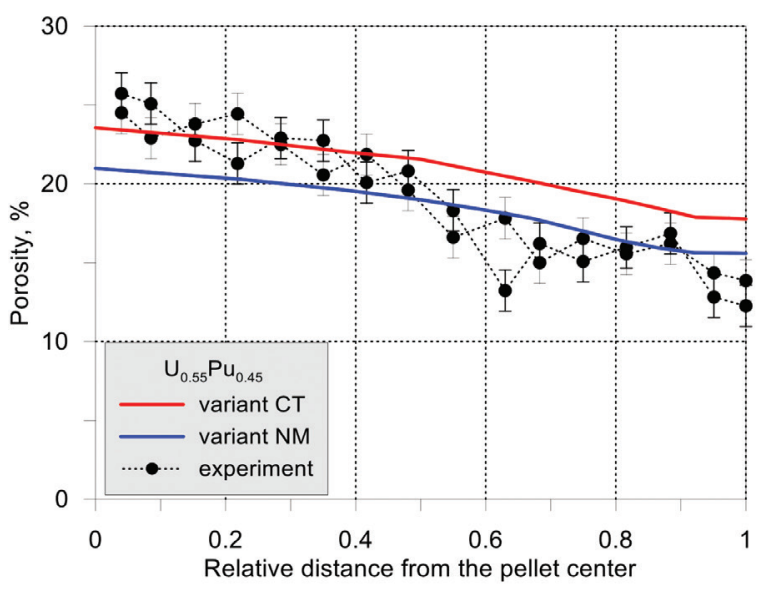

Figure 1. Radial porosity distribution in $\mathrm{U}_{0.55} \mathrm{Pu}_{0.45} \mathrm{~N}$ fuel pellets from the middle of fuel rod, BORA-BORA experiments.

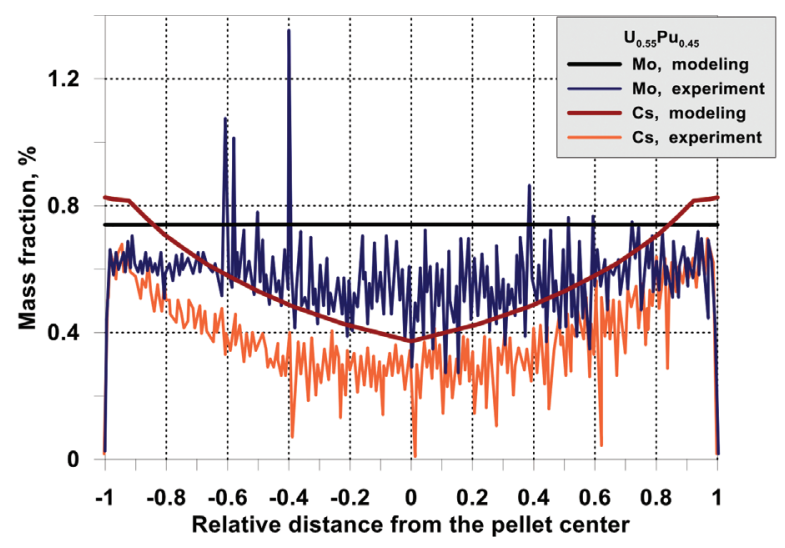

Figure 2. Radial distribution of $\mathrm{Cs}$ and $\mathrm{Mo}$ in $\mathrm{U}_{0.55} \mathrm{Pu}_{0.45} \mathrm{~N}$ fuel pellets from the middle of fuel rod, BORA-BORA experiments.

\subsection{Two-phase CFD CONV-3D/TwoPhase code}

The direct numerical simulation of Navier-Stokes equations expanded for a two-phase medium is realized in the CONV-3D/TwoPhase code. The interphase heat- and mass-transfer using the equations of state like stiffened and Noble-Abel ones are taken into account. The HLLC-solver (Harten-Lax-van-Leer-Contact) and the two-step predictor-corrector of the MUSCL algorithm (Monotonic Upwind Scheme for Conservation Laws) are realized in the module (Chudanov et al. 2019). The CFD module is adapted to massive supercomputers and is scalable in a wide range of dimensions of computational grids.

By the middle of 2019, a method for obtaining more accurate coefficient values was developed for the Nobel-Able state equations, which is based on experimental dependencies on the saturation line (temperature dependencies of gas and liquid enthalpy, inverse density of gas and liquid, saturation pressure) and applying the least square method. Based on the solution of a transcendental equation, the numerical temperature dependence of pressure is determined from the condition that the Gibbs potentials of the gas and liquid phases are equal. An adaptation of a two-phase module was carried out taking into 
account mass transfer and more accurate values of the coefficients for stiffened and Noble-Abel state equation in simulating sodium coolant flows.

The two-phase model development has been continued using the method of a priori estimates, allowing carrying out calculations with lower computational costs, without additional iterative procedures. Work on the model extension for the case of a three-component medium, for example, lead-water-vapor and other possible three-component media, has been started.

\subsection{The EUCLID/V2 multiphysics code for justifying the safety of NPPs with fast neutron reactors}

\subsubsection{Brief information}

The EUCLID/V2 ${ }^{3}$ code is designed to analyze and justify the safety of NPPs with fast neutron reactors with liquid metal coolants in the normal and abnormal operation modes, including accidents, severe ones as well (Usov et al. 2018a, 2018b; Butov et al. 2019a, 2019b). It is based on the first version of the code EUCLID/V1 (detailed information about which can be found in (Mosunova 2018; Alipchenkov et al. 2018)) and includes all of its models.

The following modules work together as part of the EUCLID/V2 calculation code, providing multi-physical consistent simulation of different processes and phenomena:

- thermohydraulic (HYDRA-IBRAE/LM), which includes a module of the FP transport and behavior, the corrosion and activation in the RI primary circuit and gas system (AEROSOL-LM), a module of solid impurity transport in the RI primary circuit with heavy liquid metal coolant (OXID), a module of tritium migration in the coolant of the first, second, and third (if available) circuits (TRITIUM);

- sub-channel module (CELSIST) for two-dimensional modeling of coolant flow in fuel assemblies;

- neutron diffusion and transport modules (DN3D and CORNER, respectively), modules for burn-up (BPSD) and decay heat (OSTB) calculation;

- fuel rod module (BERKUT and BERKUT-U) with models for calculating sources of fission products in a core in the event of fuel rod cladding failure, intended for numerical simulation of behavior and calculation of operability of nitride and oxide fuel rods;

- module for calculating the disruption of fast reactor fuel rods and other core structures (SAFR). The module implements a multicomponent one- and three-dimensional models for calculations of the movement and heat exchange of components of disrupted fuel rods and fuel assemblies in the core and upper mixing chamber of liquid-metal cooled reactor. To calculate the movement of components, the laws of conservation of mass, energy and momentum are used, as well as the equation for the sum of volume fractions of the compo-

V2 in the code name means "version 2". nents. The module also allows calculation of the movement of the formed cladding and fuel melt by gravity, friction with the gas flow and wall friction;

- module of mass transfer and FP behaviour in NPP compartments (KUPOL-BR or HYDRA-IBRAE/LM);

- module for assessing the radiation situation outside the NPP site (ROM).

The SMART/LM integration shell provides a consistent calculation by all modules.

\subsubsection{Improvement and development of individual models}

The main model improvement and development areas of the EUCLID/V2 multiphysics code in 2018-2019 include:

- development of a model which describes the transport of steam-water formations in the circuits of reactor installations with a heavy liquid-metal coolant, taking into account their size distribution;

- development of a nitride fuel dissociation model and its implementation into the code;

- improvement of the diffusion neutronic module for correct simulation of core disruption (the values of diffusion coefficients were corrected to take into account the collapse of materials during core disruption, the cross sections change due to materials flowing down during fuel rod melt was considered, etc.);

- turbine model development and integration into the code.

More detailed information about some of the models is given below.

In 2019, the model for transport of vapor-gas formations (bubbles) was added to the system thermal-hydraulic module HYDRA-IBRAE/LM of the EUCLID/ V2 code, taking into account the evolution of their size distribution. It should be noted that the description of the particle size of the dispersed phase (droplets, bubbles, vapor agglomerates) is a key point in models of two-phase media. The traditional approach used in system thermal-hydraulic codes is to determine the size of the dispersed phase from empirical correlations with instantaneous adjustment to changes in the thermal-hydraulic parameters of the carrier flow. In reality, the zone, in which a more complex than instantaneous approach is needed, can be significant (up to several meters, it depends on the flow parameters), which can be essential when analyzing, for example, the transport process of steam formations in the circuits of reactor installations with a heavy liquid-metal coolant.

The evolution of the bubble size distribution can be described more precisely by a volumetric interfacial area transport equation (Yao and Morel 2004). To solve the transport equation for the particle size distribution, the method of fractions (groups) is used in the HYDRA-IBRAE/ LM module. In this method, the set of particles is subdivided into a number of fractions (groups or classes) depending on particle size and it is assumed that there can be 
an exchange of particles between different fractions as a result of phase transitions, coagulation, fragmentation and other processes.

The experimental data on which validation of the developed models could be performed are now practically absent in the available literature. Therefore, a comparison of the calculation with the analytical solution was performed. For comparison, the article results (Gelbard and Seinfeld 1978) were used. In this work, it was obtained that with the initial distribution and the constant coagulation nucleus $\beta_{0}$, the solution is represented as

$$
n(t)=\frac{4 N_{0}}{v_{0}\left(N_{0} \beta_{0} t+2\right)^{2}} \operatorname{Exp}\left[-\frac{2 v / v_{0}}{N_{0} \beta_{0} t+2}\right]
$$

where $N_{0}$ and $v_{0}$ - parameters; $\beta_{0}$ - size-independent portion of coalescence kernel; $t$ - time; $v$ - bubble volume.

The simulation results in comparison with solution (1) from the work (Gelbard and Seinfeld 1978) are presented in Figure 3.

To our knowledge, a model of this type is not included in some well-known and widely used codes-analogous such as RELAP5-3D, ATHLET, ASTEC-Na (RELAP5-3D Code Manual 2012a, 2012b; Palazzo et al. 2013; Zhou et al. 2013; Flores et al. 2016; Bandini et al. 2018; Forgione et al. 2019; Narcisi et al. 2019; Shen et al. 2019 and many others). Similar models are available only in some CFD codes.

In 2019, a model for calculating the nitride fuel dissociation was integrated into the fuel rod destruction module of the EUCLID/V2 multiphysics code. The most important for the dissociation modeling is to determine the rate of mass loss due to release of nitrogen and uranium vapor according to the equation

$$
\left(U_{1-x} P u_{x}\right) N(\mathrm{c})=U_{1-x}(1)+P u_{x}(l)+0,5 N_{2}(\mathrm{~g})
$$

The rate of mass loss is calculated by the ratios:

$$
\begin{gathered}
\Delta m_{\left(P u_{x}, U_{1-x}\right) N}=-2 \cdot \frac{M_{\left(P u_{x}, U_{1-x}\right) N}}{M_{N_{2}}} j_{N_{2}} S \cdot \Delta t \\
\Delta m_{U}=2 \cdot \frac{(1-x) M_{U}}{M_{N_{2}}} j_{N_{2}} S \cdot \Delta t-j_{U} S \cdot \Delta t
\end{gathered}
$$

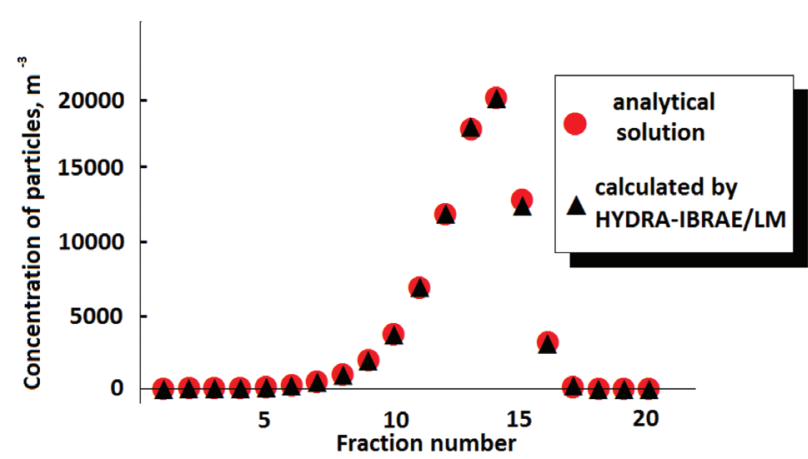

Figure 3. The results of simulation by the HYDRA-IBRAE/ LM module of the EUCLID/V2 code in comparison with the solution (1).

$$
\Delta m_{P u}=2 \cdot \frac{x \cdot M_{P u}}{M_{N_{2}}} j_{N_{2}} S \cdot \Delta t-j_{P u} S \cdot \Delta t
$$

where $j_{N_{2}}, j_{U}, j_{P u}$ - the mass flows of nitrogen, uranium and plutonium from the fuel surface; $x$ - plutonium mass fraction; $M_{N_{2}}, M_{P u}, M_{U}, M_{\left(P u_{x} U_{1-x}\right) N}-$ molar mass of nitrogen, $\mathrm{Pu}, \mathrm{U}$ and MNUP fuel, respectively; $S$ - fuel surface where the process of dissociation occurs; $\Delta t$ - time step; $\Delta m_{U}, \Delta m_{P u}, \Delta m_{\left(P u_{x} U_{1-x}\right) N}-$ changes of total masses of $\mathrm{U}, \mathrm{Pu}$ and MNUP fuel due to dissociation process respectively.

To our knowledge, this process is not modelled in codes such as SIMMER-III/IV, SOCRAT-BN (Usov et al. 2012; Cheng et al. 2015; Li et al. 2017).

\subsubsection{Validation on the results of experimental re- gimes of the $\mathrm{BN}-800 \mathrm{RI}$}

In 2015, the fourth power unit of the Beloyarsk NPP (RI BN-800 with sodium coolant) achieved its first criticality successfully, after that the first start took place. Then pilot operation of the unit was carried out. At that time, the tests of the RI main technical characteristics in stationary and transient modes at different power levels up to the nominal one were carried out. At present, the EUCLID/ V2 multiphysics code is validated on the data obtained on the $\mathrm{BN}-800$ in the following modes:

- shutdown of one of the three operating loops when the reactor is operating at a power level of $\sim 100 \% \mathrm{~N}_{\text {nom }}$;

- cooldown of the reactor by ECCS from the initial power level of $\sim 50 \% \mathrm{~N}_{\text {nom }}$;

- power unit shutdown;

- power unit start-up, where $\mathrm{N}_{\text {nom }}$ is the nominal reactor power.

The neutronics and thermohydraulic computational models of the BN-800 core, a thermal-hydraulic model of the coolant circulation circuits, including the upper mixing chamber, intermediate heat exchangers, drain chambers of intermediate heat exchangers, main circulation pumps, pressure pipe lines, pressure chamber, pipe lines of the secondary circuit, sodium buffer tank, main circulation pumps of the secondary circuit, steam generators and other equipment, as well as fuel rod models for fuel assemblies of various types are developed.

To evaluate the uncertainties and sensitivity of main RI parameters calculated using the EUCLID/V2 code, some parameters affecting the simulation results in a most significant way were determined based on previously validation calculations of experiments accounting for some individual phenomena (Table 2). The ranges of data variation were selected based on the experimental uncertainties of relevant measurements. The uncertainties of empirical correlations used in the calculations were determined in accordance with available literature data or expert estimates.

To perform the uncertainty and sensitivity analysis of the results 200 calculations have been carried out. 
Figure 4 shows a comparison of the results of multivariate calculations obtained using EUCLID/V2 code with the experimental values of integral power of the $\mathrm{BN}-800$ $\mathrm{RI}$ in the mode of "Shutdown of one of the three operating loops when the reactor is operating at a power level of $100 \% \mathrm{~N}_{\text {nom }}$ ". The intervals of calculated data are shown by blue shading. It can be seen that the deviation of the average calculated values from the experimental average ones does not exceed $5 \%$.

Figure 5 shows the EUCLID/V2 calculated values of sodium temperature in the primary loop at the IHX inlet of the BN-800 RI in the mode "Cooldown of the reactor by ECCS from the initial power level of $\sim 50 \% \mathrm{~N}_{\text {nom }}$ " in comparison with the experiment. The intervals of calculated data are shown by blue shading. The experimental uncertainties are shown by vertical bars. The maximum absolute deviation does not exceed $10 \mathrm{~K}$.

The available validation results show that for the considered types of transients, the EUCLID/V2 code describes adequately the change in the integrated power as well as the thermohydraulic processes in the BN-800 type RI core and its cooling circuits, including air circuit cooling modes.

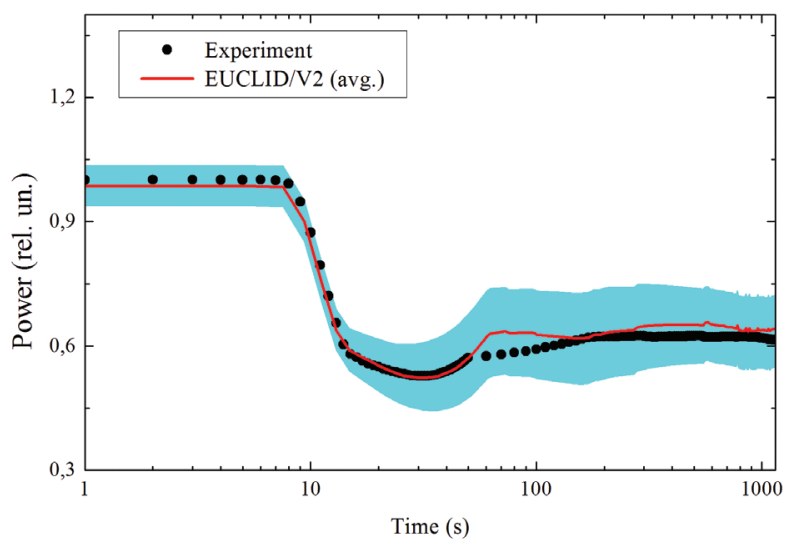

Figure 4. Change in the integral power of the BN-800 RI with time in the mode of "Shutdown of one of the three operating loops when the reactor is operating at a power level of $\sim 100 \% \mathrm{~N}_{\text {nom }}$; ( the experimental uncertainty is about $1 \%$ and is not seen in the figure)).

\subsection{Computational models of the facilities of the clo- sed nuclear fuel cycle}

In 2019, the development of calculation models for the closed nuclear fuel cycle installations was started, allowing assessing the nuclear and radiation safety of installations and selecting their optimal technological parameters. A brief description of some of the models developed is given below. Based on the spatial and phase distribution of radionuclides in the installation elements obtained in the approximations described below, the calculation of nuclear safety is performed in an automated mode by MCU-FR code and calculation of radiation safety by the COMPLEX system of codes (see Table 1).

\subsubsection{Model of the electrochemical dissolution of solid particles of plutonium and uranium oxides}

In a closed nuclear fuel cycle, spent nuclear fuel is reprocessed to extract uranium and plutonium for further re-use as fuel for fast reactors.

An important step in the technology of the spent nuclear fuel (SNF) reprocessing is the operation of further dissolving the remainder of plutonium and uranium oxide solid particles $\left(U_{x} P_{y}\right) O_{2}$ after the completion of basic technological cycles of SNF reprocessing. Its distinguishing feature is the electrochemical catalytic conversion of plutonium dioxide $\mathrm{PuO}_{2}$ from the insoluble solid phase to $\mathrm{PuO}_{2}^{2+}$ ions soluble in nitric acid $\mathrm{HNO}_{3}$ solution. A computational model was developed describing:

- real three-dimensional geometry of the installation elements;

- three-dimensional picture of medium flow in the anode and cathode volumes (CFD);

- ion transfer to electrodes with a detailed resolution of the structure of the boundary layer near the electrodes;

- heat transfer for various elements of the installation;

- sources of heat generation due to electrolysis processes and decay of radionuclides;

- migration of ions through the membrane in the approximation of transport equations for a porous medium, taking into account the electric field gradient.

Table 2. Parameters and ranges of their variation.

\begin{tabular}{|c|c|}
\hline Parameter & Variation range \\
\hline Initial integrated RC power, MW & $\pm 5 \%$ \\
\hline Residual power, MW & $\pm 25 \%$ \\
\hline The frequency of MCP-1 rotation, rpm & \pm 3.75 \\
\hline The frequency of MCP- 2 rotation, rpm & \pm 3.75 \\
\hline Feedwater flow rate in $\mathrm{SG}, \mathrm{kg} / \mathrm{s}$ & \pm 5.8 \\
\hline Speed of CPS rods, $\mathrm{cm} / \mathrm{s}$ & $\pm 5 \%$ \\
\hline Feedwater temperature in $\mathrm{SG},{ }^{\circ} \mathrm{C}$ & \pm 3.5 \\
\hline Initial diameter of fuel pellets, $\mathrm{mm}$ & -0.15 \\
\hline Multiplier applied to the wall heat transfer closure relation in SG from the water side or in AHE from the air side, rel. units & $\pm 30 \%$ \\
\hline Multiplier applied to the wall friction closure relation in SG from the water side or in AHE from the air side, rel. units & $\pm 30 \%$ \\
\hline Multiplier applied to the interfacial friction closure relation in SG for water, rel. units & $\pm 30 \%$ \\
\hline Multiplier applied to the wall heat transfer closure relation in RC, IHE and SG from the sodium side, rel. units & $\pm 20 \%$ \\
\hline Multiplier applied to the wall friction closure relation in RC, IHE and SG from the sodium side, rel. units & $\pm 10 \%$ \\
\hline Thermal conductivity of fuel, $\mathrm{W} / \mathrm{m} / \mathrm{K}$ & $\pm 20 \%$ \\
\hline Thermal conductivity of the gas gap in the fuel rod, $\mathrm{W} / \mathrm{m} / \mathrm{K}$ & $\pm 10 \%$ \\
\hline
\end{tabular}




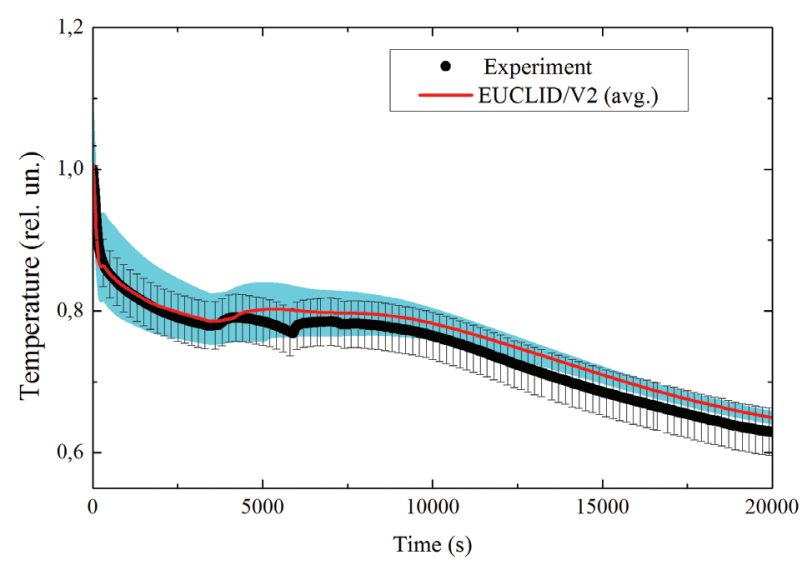

Figure 5. The change of sodium temperature in the primary loop with time at the IHX inlet of the BN-800 RI in the mode "Cooldown of the reactor by ECCS from the initial power level of $\sim 50 \% \mathrm{~N}_{\text {nom }}$ "

\subsubsection{Model of membrane clarification}

Upon the end of the cycle of electrochemical dissolution of solid particles of actinide oxides, the solution from the anode space with the remaining particles of the dispersed phase is sent to the control clarification apparatus for separating solid particles. The filtered solution containing the solid phase is delivered to a membrane filter, which contains several multichannel filtering ceramic elements that are hollow fibers coated with a membrane layer. The concentrate remains inside the channels of the filtering element, and outside the filtering element a solution is accumulated that is free from solid particles and insoluble impurities deposited in the membrane pores.

A distinctive feature of the filtered solution is the presence in the solution of liquid and solid high-level waste of SNF and ionic components. A feature of the membrane filtration process from the point of view of radiation safety is the accumulation of radioactive sediments on the surface of membrane fibers and filter walls.

The developed calculation model takes into account:

- three-dimensional hydrodynamics (CFD) of the solution flow with particles through the membrane and filter volume;

- kinetics of radioactive particles charging in nitrate electrolyte;

- possible heating of particles due to decay of radionuclides;

- thermal interaction of the dispersed and liquid phases;

- sedimentation and separation of particles from the surface of membrane channels, taking into account their charge;

- sediment formation taking into account spatial effects;

- variation in time of the sediment activity on the membrane.

\subsubsection{Model of carbothermic synthesis of nitride fuel}

Currently, the most promising option for the MNUP pellet production in industrial scale is the method of carbothermic synthesis (CTS), based on the reduction of mixed uranium-plutonium dioxide by carbon in nitrogen atmosphere.

The carbothermic synthesis reaction of $(\mathrm{U}, \mathrm{Pu}) \mathrm{N}$ is carried out with powder mixtures of uranium dioxide or uranium - plutonium, (U,Pu) $\mathrm{O}_{2}$, and graphite. Synthesis occurs at temperatures of 1700-2000 K in nitrogen stream. At the last stage of the process, some amount of hydrogen is added to nitrogen atmosphere. The role of the nitrogen flow, especially of the $\mathrm{N}_{2}+\mathrm{H}_{2}$ mixture, consists, in particular, in removing gaseous compounds of carbon and oxygen $\left(\mathrm{CO}, \mathrm{CN}, \mathrm{CH}_{4}\right)$ from the reaction zone, thus ensuring a sufficiently low concentration of oxygen and carbon impurity in the final product, which is a critical point in the production of nitride fuel by the CTS method.

There are several factors that significantly affect the CTS efficiency and the final product characteristics: the size of the particles of original powder, the presence of impurities, the temperature-time mode, the volume and composition of gas flow in the chamber. The feature of the technological process from the point of view of radiation safety is the mass loss of samples and the accumulation of radioactive dust in the CTS chamber.

The developed mathematical model for the physicochemical processes of the carbothermic synthesis of uranium and plutonium nitride powders is intended to describe the effect of process parameters - temperature, atmospheric composition, and others - on the characteristics of the products and, above all, on the concentration of impurities.

The developed calculation model takes into account:

- chemical reactions of oxygen substitution by carbon and nitrogen at the border of fuel and graphite with $\mathrm{CO}$ formation;

- chemical reactions of carbon substitution by nitrogen in the presence of hydrogen to form $\mathrm{CH}_{4}$;

- diffusive transport of oxygen, nitrogen and carbon in the solid phase;

- mass transfer of $\mathrm{N}_{2}, \mathrm{H}_{2}, \mathrm{CO}, \mathrm{CH}_{4}$ in the gas phase.

The complex mathematical model includes the heat-transfer equation, the Navier-Stokes equations, and the convection-diffusion equation.

\subsubsection{Model for sintering of nitride fuel pellets}

The final step in the process of the MNUP fuel pelletizing is sintering of fuel pellets. At the preliminary stages, the $\mathrm{UN}$ or $(\mathrm{U}, \mathrm{Pu}) \mathrm{N}$ powder is produced, which is then pressed, resulting in an intermediate product with a density of $\sim 60 \%$ having sufficient mechanical strength and the 
required chemical composition. At the sintering stage, a part of the fuel main characteristics is formed, such as density, size and type of porosity, grain size, determining the fuel performance.

There are several factors that significantly affect the sintering efficiency of $(\mathrm{U}, \mathrm{Pu}) \mathrm{N}$ and the characteristics of the final product: the size and shape of the particles of the original powder, the initial porosity of the sample, the sintering temperature and time, and the atmosphere in the sintering chamber.

The developed computational model takes into account the following processes:

- fuel recrystallization by the mechanisms of normal grain growth and re-condensation;

- relaxation of intergranular porosity due to the diffused drain of vacancies and external thermo-mechanical stresses;

- thermochemical reactions, leading to a mass loss of the sample.

In the constructed computational model, three-dimensional heat transfer in a complex furnace design, mass transfer of the gas mixture in the working area, multicomponent diffusion and reactions in fuel grains are described consistently.

\section{Experiments to validate the codes of new generation}

To validate the developed and being developed codes of new generation, it was necessary to create a database of evaluated available experimental data. For this, the analysis and evaluation of the results of experimental studies conducted prior to the start-up of the "PRORYV" Project were carried out. According to the analysis results, work programs for obtaining the missing experimental data were prepared. At the same time, validation of a number of high fidelity codes required experimental data obtained at a fundamentally new level with the measurement of local flow characteristics.

In this regard, a program of experimental studies of thermal-hydraulic and physicochemical processes is developed, and the studies are performed at JSC "NIKIET" (Moscow), JSC “SSC RF - IPPE” (Obninsk, Russia), IT SB RAS (Novosibirsk, Russia) and other organizations.

In particular, at the IT SB RAS a series of well-instrumented model experiments has been performed to study the heat transfer and thermohydraulic characteristics of a heavy liquid-metal coolant in the elements of a reactor installation, including the processes occurring during steam generator tube rupture of lead cooled reactor installation (Kashinsky et al. 2016; Lobanov et al. 2017; Kashinsky et al. 2018; Usov et al. 2018c).
Various outflow regimes (bubble, slug) when water vapor or gas is flowing out into a lead or Rose's alloy coolants, modeling the steam generator tube rupture in fast reactors facilities, and the heat transfer between water vapor and lead coolant have been studied (Lobanov et al. 2017; Usov et al. 2018c). The lead temperature during experiments was about $400{ }^{\circ} \mathrm{C}$, the Rose's alloy - about $150{ }^{\circ} \mathrm{C}$. The outflow of water vapor / gas occurred through the tubes with a diameter of $2-4 \mathrm{~mm}$. In the different series of experiments, the pressure drop between the steam (gas) and the coolant and the time of the outflow of water vapor (gas) were changed. The evolution and size of steam or inert gas bubbles in lead were measured. The regimes of steam / gas outflow were found in which large pressure pulsations are formed in the channel. Also the data on lead temperature evolution were obtained in the experiments with outflow of "cold" water vapor or inert gas into the lead. The obtained experimental data were used to validate the calculation code HYDRA-IBRAE/LM (Usov et al. 2018c).

The experiments on mixing of liquid metal coolant flows at different temperatures in a T-junction were conducted (Kashinsky et al. 2016; Kashinsky et al. 2018). The T-junction consists of two pipes with internal diameters of 8 and $20 \mathrm{~mm}$ connected perpendicularly. The liquid metal coolant was a melt of Rose's alloy (50\% bismuth, $25 \%$ lead, $25 \%$ tin). The temperature of the "hot" flow was about $150^{\circ} \mathrm{C}$, of the "cold" flow about $120^{\circ} \mathrm{C}$, flow rate ratios of the "hot" and "cold" flows were varied in the range between 0,02 and 0,63 . The Reynolds numbers of the "cold" flow in the pipe were in the range $6500 \div 14500$. As a result of the measurements, three-dimensional distributions of the average temperatures and temperature fluctuations were obtained both on the external surface of the T-junction and directly in the flow mixing area. Those data were used to validate RANS and DNS codes (LOGOS, CONV-3D, STAR-CCM+ and others).

In the experiments with a 7-rods model of a fuel assembly with spacer grids detailed data on the axial and azimuthal temperature distributions over the surface of the fuel rod simulators with nonuniform heating of one of the fuel rods, and the data on the impact of the spacer grids on the temperature field distribution on the surface of the fuel rod simulator were obtained (Kashinsky et al. 2018). The fuel assembly model consisted of 7 vertical rods with a diameter of $9 \mathrm{~mm}$, arranged in a hexagonal pattern with a relative pitch between the rods equal to 1.4. The investigations were carried out at Reynolds number values 8000 and 14000 and the heat flux density $19.6 \mathrm{~W} /$ $\mathrm{cm}^{2}$ using Rose's alloy. An example of the typical axial sweep of the radial temperature distribution behind the spacer grid, when the peripheral simulator of the fuel element is heated, is shown in Figure 6. As one can see, a large irregularity of temperature distribution is observed. The experiments are conducted not only in the field of thermohydraulic. In the coming years, JSC "IRM" (Zarechniy, Russia) is planning to obtain reactor experimental 
data and dependencies of the outflow kinetics of gaseous fission products released from the MNUP fuel required for setting the parameters of the models and validating the BERKUT-U fuel rod code. At the same time, tests of the MNUP fuel behavior after reactivity introduction will be conducted in the IGR reactor. The irradiation of experimental fuel assemblies and devices with MNUP fuel rods in the BN-600 and BOR-60 RI continues.

The obtained data are used for the validation of the multiphysics codes of new generation and the fuel rod codes.

Those are only some of the examples demonstrating that work on the code development is accompanied by the extensive program of experimental investigations.

\section{Conclusion}

In the "Codes of new generation" subproject of the "PRORYV" Project, the software was developed to justify the safety of the facilities being constructed, to understand the phenomenology of the processes, to optimize equipment and installations in general. High fidelity models and calculation codes based on them make possible to carry out predictive calculations in order to achieve optimal technical and economic indicators of the developed nuclear technologies.

A large effort on certification in Rostechnadzor of the developed software is being performed. At the same time, the principal novelty of the approaches underlying the creation of high precision software products requires changes in the accepted certification practice and the creation of an appropriate new infrastructure, including highly qualified experts for individual profiles, the agreement between the code developers and the regulator, formalized as the regulatory documents, on the necessary and sufficient experimental data and the limits of applicability of the corresponding tools, the formation of the "best practices" for the use of high fidelity codes at specific facilities.

Since the increasingly restrictive requirements are imposed on the safety justification of nuclear facili-

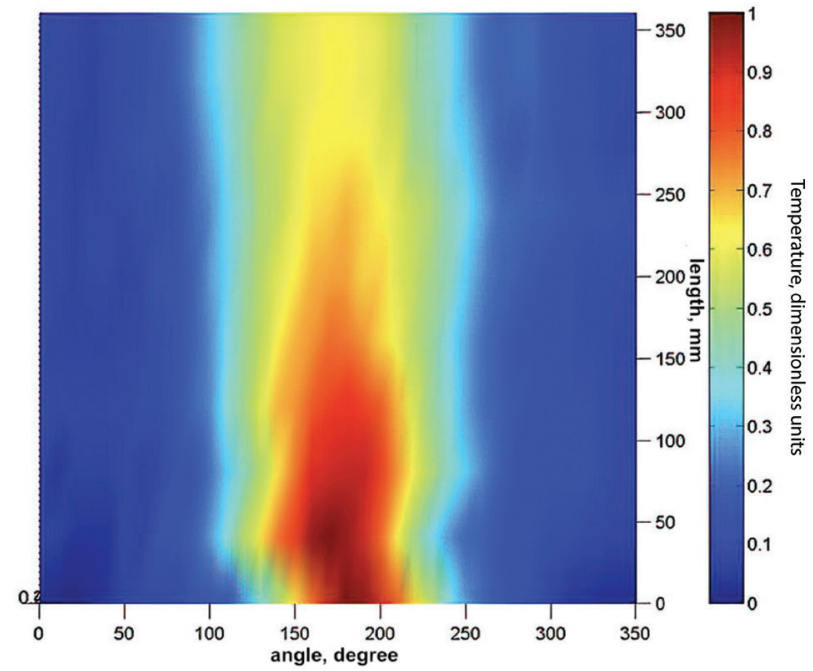

Figure 6. Typical axial sweep of the radial temperature distribution on the surface of the central fuel rod simulator behind the spacer grid. Rose's alloy: $\mathrm{T}=150{ }^{\circ} \mathrm{C}, \mathrm{Re}=8000$.

ties, in terms of detailed elaboration of models, many calculation codes in the nuclear industry are ahead of analogues that are available or are only planned to be developed in other industries. In this regard, the codes of new generation may be applied outside the nuclear industry, for example, to assess the effects of emissions from enterprises in other industries, to assess the impact on humans and the environment of facilities that pose a potential environmental hazard.

A program for the further development of codes of new generation has been outlined, including their validation on new experimental data, the creation of high precision models, and the introduction of the developed software into the practice of computational justification of nuclear facilities safety. To form a team of qualified users, it is planned to implement the developed software into higher educational institutions and hold annual user-training workshops.

\section{References}

- Abramov LV, Bakhmetyev AM, Bylov IA, Vasyuchenkov AA (2016) Development and verification of a software system for probabilistic safety analysis of nuclear installations project direction "PRORYV”. Izvestiya vuzov. Yadernaya Energetika 1: 5-12. https://doi. org/10.26583/npe.2016.1.01

- Alipchenkov VM, Anfimov AM, Afremov DA, Gorbunov VS, Zeigarnik YuA, Kudryavtsev AV, Osipov SL, Mosunova NA, Strizhov VF, Usov EV (2016) Fundamentals, Current State of the Development of, and Prospects for Further Improvement of the New-Generation Thermal-Hydraulic Computational HYDRA-IBRAE/LM Code for Simulation of Fast Reactor Systems. Thermal Engineering 63: 2: 130-139. https://doi.org/10.1134/S0040601516020014

- Alipchenkov VM, Boldyrev AV, Veprev DP, Zeigarnik YA, Kolobaeva PV, Moiseenko EV, Mosunova NA, Seleznev EF, Strizhov VF,

Usov EV, Osipov SL, Gorbunov VS, Afremov DA, Semchenkov AA (2018) The EUCLID/V1 Integrated Code for Safety Assessment of Liquid Metal Cooled Fast Reactors. Part 2: Validation and Verification. Thermal Engineering 65: 9: 627-640. https://doi.org/10.1134/ S004060151809001X

- Bandini G, Ederli S, Perez-Martin S, Haselbauer M, Pfrang W, Herranz LE, Berna C, Matuzas V, Flores y Flores A, Girault N, Laborde L (2018) ASTEC-Na code: Thermal-hydraulic model validation and benchmarking with other codes. Annals of Nuclear Energy 119: 427-439. https://doi.org/10.1016/j.anucene.2017.12.016

- Belousov VI, Grushin NA, Sychugova EP, Seleznev EF (2018) Some results of verification of code ODETTA for shielding calculations. Problems of Atomic Science and Technology. Series: Physics of nuclear reactors 3: 46-53. (in Russian) 
- Belov AA, Bereznev VP, Seleznev EF, Shkarovsky DA, Zherdev GM (2019) Program complex for radiation safety calculation. Problems of Atomic Science and Technology. Series: Nuclear and Reactor Constants 2: 243-255 (in Russian).

- Bereznev VP, Seleznyov EF, Asatrian DS (2015) The «CORNER» neutronics calculation code. Proceedings of Higher Educational Institutions, Physics and technology of nuclear reactors 1: 136-143 (in Russian). https://doi.org/10.26583/npe.2015.1.15

- Boldyrev AV, Zadorozhnyi AV, Ozrin VD, Tarasov VI, Dolinskii IO, Chernov SY (2020) BERKUT code validation on post-reactor studies of irradiated BN-600 fuel rods with mixed uranium-plutonium nitride fuel. Atomic Energy 127: 6: 356-361. https://doi.org/10.1007/ s10512-020-00636-0

- Bol'shov L.A., Mosunova NA, Strizhov VF, Shmidt OV (2016) Next generation design codes for a new technological platform for nuclear power. Atomic Energy 120: 6: 369-379. https://doi.org/10.1007/ s10512-016-0145-4

- Butov AA, Zhdanov VS, Klimonov IA, Kudashov IG, Kutlimetov AE, Lobanov PD, Mosunova NA, Sorokin AA, Strizhov VF, Usov EV, Chukhno VI (2019a) Verification of the EUCLID/V2 Code Based on Experiments Involving Destruction of a Liquid Metal Cooled Reactor's Core Components. Thermal Engineering 66: 5 302-309. https://doi.org/10.1134/S0040601519050033

- Butov AA, Zhdanov VS, Klimonov IA, Kudashov IG, Kutlimetov AE, Mosunova NA, Strizhov VF, Sorokin AA, Frolov SA, Usov EV, Chukhno VI (2019b) The EUCLID/V2 code physical models for calculating fuel rod and core failures in a liquid metal cooled reactor. Thermal Engineering 66: 5: 293-301. https://doi.org/10.1134/S0040601519050021

- Cheng S, Matsuba K-I, Isozaki M, Kamiyama K, Suzuki T, Tobita Y (2015) A numerical study on local fuel-coolant interactions in a simulated molten fuel pool using the SIMMER-III code. Annals of Nuclear Energy 85: 740-752. https://doi.org/10.1016/j.anucene.2015.06.030

- Chudanov VV, Aksenova AE, Leonov AA, Makarevich AA (2016) Development of a Multidimensional Method for the Interaction of Liquid-Gas Two-Phase Flows with Formation of an Interphase Boundary. Atomic Energy 120: 1: 29-36. https://doi.org/10.1007/ s10512-016-0091-1

- Chudanov VV, Aksenova AE, Makarevich AA, Pervichko VA (2017) CONV-3D code application for CFD-modeling of lead-bismuth coolant. Atomic Energy 123: 2: 87-92. https://doi.org/10.1007/ s10512-017-0306-0

- Chudanov VV, Aksenova AE, Leonov AA (2019) Method of solving problems of two-phase heat- and hydrodynamics with sodium coolant. Atomic Energy 125: 4: 224-230. https://doi.org/10.1007/ s10512-019-00471-y

- Chudanov VV, Aksenova AE, Pervichko VA (2020) Modeling of incompressible fluid flows in a round tube in laminar, transient, and turbulent regimes using the CONV-3D code. Atomic Energy 127: 5: 328-332. https://doi.org/10.1007/s10512-020-00631-5

- Dzama DV, Semenov VN, Sorokovikova OS, Fokin AL (2019a) Methods for estimation of radiation situation through emergency release from NPP with use of real meteorological data. Safety and emergencies problems 3: 36-44 (in Russian).

- Dzama DV, Sorokovikova OS, Asfandiyarov DG (2019b) Physical and mathematical multifunctional models, specialized numerical algorithms and software for modeling of propagation of contamination taking into account three-dimensional urban or industrial building.
In: Numerical algebra with applications. Proceedings of Eighth China-Russia Conference. Southern Federal University, I.I. Vorovich Institute of Mathematics, Mechanics, and Computer Science. 124-129.

- Flores y Flores A, Matuzas V, Perez-Martin S, Bandini G, Ederli S, Ammirabile L, Pfrang W (2016) Analysis of ASTEC-Na capabilities for simulating a loss of flow CABRI experiment. Annals of Nuclear Energy 94: 175-188. https://doi.org/10.1016/j.anucene.2016.02.032

- Forgione N, Martelli D, Barone G, Giannetti F, Lorusso P, Hollands T, Papukchiev A, Polidori M, Cervone A, Di Piazza I (2019) Post-test simulations for the NACIE-UP benchmark by STH codes. Nuclear Engineering and Design 353: 110279. https://doi.org/10.1016/j.nucengdes.2019.110279

- Gelbard F, Seinfeld JH (1978) Numerical solution of the dynamic equation for particulate systems. Journal of Computational Physics 28: 3: 357-375. https://doi.org/10.1016/0021-9991(78)90058-X

- Goryunov AG, Egorova OV, Kozin KA, Liventsov SN, Liventsova NV, Shmidt OV (2018) Optimization and diagnostics code for technological processes: radiochemical production simulator. Atomic Energy 124: 5: 321-325. https://doi.org/10.1007/s10512-018-0417-2

- Gurevich MI, Kalugin MA, Oleynik DS, Shkarovskiy DA (2016) Features of MCU-FR. Problems of Atomic Science and Technology. Series: Physics of nuclear reactors 5: 17-21. (in Russian)

- Kalugin MA, Oleynik DS, Shkarovsky DA (2015) Overview of the MCU Monte Carlo software package. Annals of nuclear energy 82: 54-62. https://doi.org/10.1016/j.anucene.2014.08.032

- Kapyrin IV, Ivanov VA, Kopytov GV, Utkin SS (2015) Integral code GeRa for RAW disposal safety validation. Gornyi Zhurnal 10: 44 50. https://doi.org/10.17580/gzh.2015.10.08

- Kashinsky ON, Lobanov PD, Kurdyumov AS, Pribaturin NA (2016) Modeling the flow of liquid-metal coolant in the T-shaped mixer. 2016. Thermophysics and Aeromechanics 23: 3: 379-382. https:// doi.org/10.1134/S0869864316030070

- Kashinsky ON, Kurdyumov AS, Lobanov PD, Svetonosov AI, Vorobyev MA, Pribaturin NA (2018) Experimental activities on thermal hydraulics of heavy liquid metal flow in typical elements of nuclear power stations. In: Proceedings of the $26^{\text {th }}$ International Conference on Nuclear Engineering (ICONE 26), July 22-26, 2018, London, England, ICONE26-82407, 7.

- Kozelkov AS, Kurulin VV, Lashkin SV, Shagaliev RM, and Yalozo AV (2016) Investigation of Supercomputer Capabilities for the Scalable Numerical Simulation of Computational Fluid Dynamics Problems in Industrial Applications, Computational Mathematics and Mathematical Physics 56: 8: 1506-1516. https://doi.org/10.1134/ S0965542516080091

- Krylov AL, Nosov AV, Kiselev VP (2016) Verification of the multi-chamber model of radioactivity migration in reservoirs. Russian Meteorology and Hydrology 41: 5: 344-350. https://doi. org/10.3103/S1068373916050058

- Li R, Chen X-N, Andriolo L, Rineiski A (2017) 3D numerical study of LBE-cooled fuel assembly in MYRRHA using SIMMER-IV code. Annals of Nuclear Energy 104: 42-52. https://doi.org/10.1016/j.anucene.2017.02.009

- Lobanov PD, Usov EV, Butov AA, Pribaturin NA, Mosunova NA, Strizhov VF, Chukhno VI, Kutlimetov AE (2017) Experimental investigation of the impulse gas injection into liquid and the use of experimental data for verification of the HYDRA-IBRAE/LM thermohydraulic code. Thermal Engineering 64: 10: 770-776. https:// doi.org/10.1134/S004060151710007X 
- Mosunova NA (2018) The EUCLID/V1 Integrated Code for Safety Assessment of Liquid Metal Cooled Fast Reactors. Part 1: Basic Models. Thermal Engineering 65: 5: 304-316. https://doi. org/10.1134/S0040601518050063

- Mosunova NA, Alipchenkov VM, Pribaturin NA, Strizhov VF, Usov EV, Lobanov PD, Afremov DA, Semchenkov AA, Larin IA(2020) Lead coolant modeling in system thermal-hydraulic code HYDRA-IBRAE/ LM and some validation results. Nuclear Engineering and Design 359. 1104631: 11. https://doi.org/10.1016/j.nucengdes.2019.110463

- Narcisi V, Giannetti F, Caruso G (2019) Investigation of RELAP5-3D capability to predict thermal stratification in liquid metal pool-type system and comparison with experimental data. Nuclear Engineering and Design 352: 110152. https://doi.org/10.1016/j.nucengdes.2019.110152

- Novikov K, Kapyrin I (2020) Coupled surface-subsurface flow modelling using the GeRa software. Lobachevski journal of mathematics 41: 4: 538-551. https://doi.org/10.1134/S1995080220040162

- Palazzo S, Velkov K, Lerchl G, Van Tichelen K (2013) Analyses of the MYRRHA spallation loop using the system code ATHLET. Annals of Nuclear Energy 60: 274-286. https://oi.org/10.1016/j. anucene.2013.05.010

- RELAP5-3D (2012) RELAP5-3D Code Manual Volume I: Code Structure, System Models and Solution Methods, INEEL-EXT-98-00834, Revision 4.0, June 2012.

- RELAP5-3DC Code Manual. Volume IV: Models and Correlations INEEL-EXT-98-00834, Revision 4.0, June 2012.

- Rogozkin BD, Stepennova NM, Fedorov Yu.Ye, Shishkov MG, Kryukov FN, Kuzmin SV, Nikitin ON, Belyaeva AV, Zabudko LM (2013) Results of irradiation of (U0.55Pu0.45)N and (U0.4Pu0.6)N fuels in BOR-60 up to $\sim 12$ at.\% burn-up. Journal of Nuclear Materials 440: 1-3: 445-456. https://doi.org/10.1016/j.jnucmat.2013.04.033

- Seleznev EF, Belov AA, Belousov VI, Chernova IS, Drobyshev YY (2018a) DOLCE VITA. Problems of Atomic Science and Technology. Series: Nuclear and Reactor Constants 1: 157-168 (in Russian)

- Seleznev EF, Belov AA, Belousov VI, Chernova IS (2018b) BPSD code upgrade for solving the nuclear kinetics problem. Proceedings of Higher Educational Institutions. Nuclear Power Engineering 4: 115-127 (in Russian). https://doi.org/10.26583/npe.2018.4.10

- Shen C, Zhang X, Wang C, Cao L, Chen H (2019) Transient safety analysis of $M^{2}$ LFR-1000 reactor using ATHLET. Nuclear Engineering and Technology 51: 116-124. https://doi.org/10.1016/j net.2018.08.011

- Shmidt OV, Tret'yakova SG, Evsyukova YA, Makeeva IR, Dubosarskii VG, Pugachev VY, Rykunova AA (2017) VIZART software for balance calculations of material flows in closed nuclear fuel cycle technologies. Atomic Energy 122: 2: 106-111. https://doi org/10.1007/s10512-017-0243-y

- Starikov SV, Kuksin AJu, Smirnova DE, Dolgodvorov AP, Ozrin VD (2017) Multiscale modeling of uranium mononitride: point defects diffusion, self-diffusion, phase composition. Defect and Diffusion Forum 375: 101-113. https://doi.org/10.4028/www.scientific.net/DDF.375.101

- Strizhov V, Bolshov L, Mosunova N (2017) Codes of new generation developed for BREAKTHROUGH project. Books of abstracts of the International Conference on Fast Reactors and Related Fuel Cycles: Next Generation Nuclear Systems for Sustainable Development (FR17), 26-29 June 2017, Yekaterinburg, Russian Federation, IAEA-CN245-184, 440.

- Tarasov VI, Polovnikov PP (2017) MFPR model parameters of the athermal irradiation-induced transport in nuclear fuels. Defect and
Diffusion Forum 375: 71-83. https://doi.org/10.4028/www.scientific.net/DDF.375.71

- Usov EV, Kudashov IG, Zhigach SA, Butov AA, Pribaturin NA, Lezhnin SI, Chalyy RV, Yakush SE, Vinogradova U (2012) Coupled code SOCRAT-BN development for safety analysis of sodium-cooled fast reactors. International Conference on Nuclear Engineering, Proceedings, ICONE, 2: 1: 361-366. https://doi.org/10.1115/ICONE20-POWER2012-54316

- Usov EV, Butov AA, Chukhno VI, Klimonov IA, Zhdanov VS, Pribaturin NA, Mosunova NA, Strizhov VF, Kudashov IG (2018a) SAFR/V1 (EVKLID/V2 integral code module) aided simulation of melt movement along the surface of a fuel element in a fast reactor during a serious accident. Atomic Energy 124: 4: 232-237. https:// doi.org/10.1007/s10512-018-0403-8

- Usov EV, Butov AA, Chukhno VI, Klimonov IA, Kudashov IG, Zhdanov VS, Pribaturin NA, Mosunova NA, Strizhov VF (2018b) Fuel pin melting in a fast reactor and melt solidification: simulation using the SAFR/V1 module of the EVKLID/V2 integral code. Atomic Energy 124: 3: 147-153. https://doi.org/10.1007/s10512-018-0389-2

- Usov EV, Lobanov PD, Kutlimetov AE, Kudashov IG, Chukhno VI, Lezhnin SI, Pribaturin NA, Kashinsky ON, Svetonosov AI, Mosunova NA (2018c) Experimental Simulation of Hydrodynamics and Heat Transfer in Bubble and Slug Flow Regimes in a Heavy Liquid Metal. Thermal Engineering 65: 8: 562-567. https://doi.org/10.1134/ S0040601518080086

- Veprev DP, Boldyrev AV, Chernov SY, Mosunova NA (2018) Development and validation of the BERKUT fuel rod module of the EUCLID/V1 integrated computer code. Annals of Nuclear Energy 113: 237-245. https://doi.org/10.1016/j.anucene.2017.11.038

- Veprev DP, Boldyrev AV, Chernov SY (2020) Validation of the BERKUT fuel rod module against mixed nitride fuel experimental data. Annals of Nuclear Energy 135: 106963: 8. https://doi.org/10.1016/j. anucene.2019.106963

- Veshchunov MS, Ozrin VD, Shestak VE, Tarasov VI, Dubourg R, Nicaise G (2006) Development of the mechanistic code MFPR for modelling fission-product release from irradiated $\mathrm{UO}_{2}$ fuel. Nuclear Engineering and Design 236: 2: 179-200. https://doi.org/10.1016/j. nucengdes.2005.08.006

- Veshchunov MS, Dubourg R, Ozrin VD, Shestak VE, Tarasov VI (2007) Mechanistic modelling of urania fuel evolution and fission product migration during irradiation and heating. Journal of $\mathrm{Nu}$ clear Materials 362: 2-3: 327-335. https://doi.org/10.1016/j.jnucmat.2007.01.081

- Veshchunov MS, Boldyrev AV, Kuznetsov AV, Ozrin VD, Seryi MS, Shestak VE, Tarasov VI, Norman GE, Kuksin AYu, Pisarev VV, Smirnova DE, Starikov SV, Stegailov VV, Yanilkin AV (2015) Development of the advanced mechanistic fuel performance and safety code using the multi-scale approach. Nuclear Engineering and Design 295: 116-126. https://doi.org/10.1016/j.nucengdes.2015.09.035

- Vitushkina NM, Luk'yanov AA, Shan'gin NN (2006) Simulating spatial effects during condensation of steam in a model containment using the KUPOL-3D computer code. Thermal Engineering 53: 9: 749-754. https://doi.org/10.1134/S004060150609014X

- Yao W, Morel C (2004) Volumetric interfacial area prediction in upward bubbly two-phase flow. International Journal of Heat and Mass Transfer 47: 307-328. https://doi.org/10.1016/j.ijheatmasstransfer.2003.06.004

- Zhou C, Huber K, Cheng X (2013) Validation of the modified ATHLET code with the natural convection test of the PHENIX reactor. Annals of Nuclear Energy 59: 31-46. https://doi.org/10.1016/j.anucene.2013.03.035 